Editorial

\title{
Shifting to healthier cities with improved urban ecological infrastructure: From the perspectives of planning, implementation, governance and engineering
}

\section{Keywords:}

Urban ecological infrastructure

Ecosystem services

Impervious surfaces

Wetlands

Waste management

Urban transport

\begin{abstract}
A B S T R A C T
Ecosystem services losses have worsened already serious urban problems such as heat island effects, urban flooding, and biodiversity losses. Urban ecological infrastructure (UEI) is the main carrier of ecosystem services in urban areas and provides a promising approach to combat such urban challenges and at the same time increases urban sustainability and resilience. The objectives of this special volume (SV) were to provide systematic reviews and discussions of the new governance, engineering and technologies available for improving UEI, which can be used to promote the development application of improved urban ecological engineering theories, methods and tools. Seven themes are included in this SV: (1) From civil infrastructure to ecological infrastructure: diagnoses and remedies of urban illnesses; (2) International experiences and lessons in urban "green-blue" ecological engineering to develop and to enforce standards for restoration of natural and social ecosystem services; (3) Implementation of integrated urban waste management, recycling and treatment policies and facilities; (4) Design and modify urban impervious surfaces through ecological engineering; (5) Urban aorta ecology, ecological mobility and livable corridors; (6) Integrative design criteria and cases of urban ecological infrastructure management; (7) The roles of urban ecological infrastructure in industrial parks and industrial clusters. This SV included forty-one, high-quality papers on theories and practices in UEI and in urban sustainability. Concepts, principles, theories, innovative assessment models, successful experiences, barriers to and enablers of UEI implementation were discussed. The authors provide a solid foundation and foster new inspiration to catalyze more ecologically sound and sustainable urbanization.
\end{abstract}

ㄷ) 2016 Elsevier Ltd. All rights reserved.

\section{Introduction}

Rapid urbanization is an increasingly dominant transformation of our time (Hartig and Kahn, 2016). Between 1950 and 2005, the level of urbanization increased from $29 \%$ to $49 \%$, while global carbon (C) emissions from fossil-fuel burning increased by almost 500\% (UN-Habitat, 2016). Despite economic and social progress, the rapid urbanization generates serious ecological stressors for ecosystems and for human health, thus resulting in the loss of ecosystem services, environmental degradation and increasing incidence of numerous types of human diseases. Urbanization alters the environment in many ways, from causing habitat fragmentation and biodiversity losses to urban flooding and dramatic increases in severity of air and water pollution. In particular, the increases in impervious surfaces, is leading to increasingly severe urban floods and droughts, increased heat island effects, increased air quality problems and biodiversity losses (McDonnell and MacGregor-Fors, 2016; Nicholas et al., 2016).

Despite the stressors and risks from rapid urbanization, there is under-investment in improved urban infrastructure. Globally, U\$ 57 trillion will be needed for infrastructure investment between 2013 and 2030 to support economic growth and improved urbanization (UN-Habitat, 2016). This is of particular concern for developed countries, where people in many large cities experience serious congestion, and for developing countries, where improved basic socioeconomic conditions have been long overdue (UNHabitat, 2016). Thus, it is imperative to promote a new type of urbanization to reduce the environmental impacts of economic and population growth and to foster the development of healthy and sustainable cities.

Urban ecological infrastructure (UEI) is defined as the organic integration of blue (water-based), green (vegetated), and gray (non-living) landscapes, combined with "exits" (outflows, treatment, or recycling) and "arteries" (corridors) at an ecosystem scale. The UEI approaches play fundamental roles in sustainably providing the ecosystem services that urban residents require. The UEIs include a comprehensive set of functions: water supply and recycling; energy supply and heat dissipation; soil fertility 
and biodiversity; materials breakdown and utilization of currently wasted materials; reduction of runoff and improved nutrient retention; and improved recreational, educational and cultural service provision (Li et al., 2017c).

The UEIs have evolved during the last three decades; they are commonly referred to as the connective matrices of green spaces, wetlands, ecological corridors, impervious surfaces, and traditional gray infrastructure (Li et al., 2017a). The concept of ecological infrastructure was first introduced in a report by the United Nations Educational, Scientific, and Cultural Organization (UNESCO) on the Man and Biosphere (MAB) Program in 1984. During the 1990s, the concept of UEIs were used in theoretical and practical research (Gates and Giffen, 1991; Hanski, 1997). In China, Yu et al. (2007) first applied the concept of UEIs to urban spatial planning. After 30 years of development, the multiple benefits of UEI have become accepted by scientists, governmental leaders, urban planners and the public. The UEIs haves become an indispensable approach for national strategies such as the "sponge city construction", the core idea of which is to increase adaptation and resilience to environmental changes and hazards. To actively contribute to the discourse of this new urbanization, the Chinese Academy of Engineering and the International Council on Ecopolis Development, jointly organized an International Ecopolis Forum on "Urban Ecological Infrastructure for New Urbanization: Engineering and Management," which was held in Beijing on Nov. 28-30, 2013. The experiences of and ideas from international researchers, engineers, policy makers and entrepreneurs were discussed during this event, and one of the results of that joint conference is this special volume (SV) of the Journal of Cleaner Production (JCLP). Following the event in 2013, the International Conference on Sustainable Infrastructure was held in Shenzhen in 2016 to further explore the discourse of sustainable urban development through sustainable infrastructure construction.

This SV includes cutting-edge papers that focused upon promoting the theories, ideas and practices involved in ecological infrastructure for healthier cities. This SV includes papers with broad perspectives on urban planning, engineering, technology, and management to improve the role of UEI in combating common challenges such as climate changes, biodiversity losses and pollution so that cities can become more livable and sustainable.

\section{Objectives of this special volume}

The objectives of this SV were to contribute to the systematic review and discussion of the new governance, engineering and technologies available for improving UEIs, which can promote the development of improved urban ecological engineering theories, methods and tools. This SV provides scientific knowledge and practical approaches for the prevention and control of urban water and air pollution, haze, smog, heat island effects, soil pollution and ecosystem service losses and reductions in the extent of natural habitats. This SV specifically focused on designs that integrate gray infrastructure and green infrastructure at multiple scales and on how UEI, as a system, generates natural, economic and social benefits that increase cities' adaptation and resilience.

This SV addressed three dimensions by which urban sustainability can be improved through the UEI approaches:

1) On a theoretical level, the SV included the fundamental concepts, principles, benchmarks and targets of UEI management, the coupling mechanism of UEI's structure and its services and systematic models for UEI integration and regulation.

2) On the engineering and technology levels, it included innovative engineering and technology developments and applications, UEI's performance and the risks modeling, as well as a library of engineering techniques and technologies developed for diverse natural, social and economic contexts.

3) On the planning and management levels, it involved the use of systematic planning methods for UEI at multiple scales; a model for assessing UEI system performance, barriers, and enablers and opportunities in UEI implementation; and examples of successful cases of increasing stakeholders' involvement in UEI management.

\section{Overview of the papers included in this SV}

Forty-one papers were accepted, which are included within the seven themes of this SV. Detailed information of the titles of the papers of each theme are presented in Table 1. Theme one was addressed in fourteen papers, with topics spanning urban metabolism, particularly energy consumption and carbon emissions, sustainability assessment, water footprint evaluation, urban air pollution and its health impact.

Ten papers addressed theme two, by discussing cultural, economic and natural ecosystem services; successful experiences; improved design; and institutional and policy-related factors in green and blue infrastructure implementation.

Themes three, four, and five were addressed by fewer papers, which suggests the need for more studies in these areas. The JCLP has previously published numerous studies about solid and liquid waste management; Interested readers are invited to access the relevant articles published during 23 years of publication of the JCLP.

The impact of impervious surfaces and urban transportation infrastructure have attracted extensive attention recently. However, owing to methodological difficulties, relevant studies are still scarce. Integrative models which could assess and predict the multiple ecological impacts of impervious surfaces on air, water, heat environment and vegetation require further exploration. Transportation is a key factor in determining the pattern of development and the matter, energy and information flows of cities. Transportation causes diverse types of pollution, habitat fragmentation, and biodiversity losses. Thus, sustainable transport systems can or must play an important role in catalyzing sustainable cities and require further study.

Seven papers, including two reviews, were included on theme six. These papers addressed topics such as sustainable neighborhoods and lifestyle, green buildings and rural-urban coordinated development. More studies of the integrative design of UEI under different natural, social and economic contexts are required. Four papers contributed to theme seven. The metabolism and environmental performance of different industrial sectors and industrial parks were examined. Additional studies of the UEI design for various industrial parks, the proper management of industrial wastes and the multiple benefits generated by UEI are urgently needed.

A detailed introduction of each paper is presented in the following sections of this introduction.

\subsection{Theme one: from civil infrastructure to ecological infrastructure: diagnoses and remedies of urban illnesses}

Over $75 \%$ of global resource and energy consumption and $80 \%$ of C-emissions occurred in cities (UN, 2012). The consumption of resources and the discharge of wastes in urban areas cause many serious ecological impacts at local and global scales (Bai, 2007). In 1965, Wolman (1965) proposed the urban metabolism (UM) concept to summarize the ideas of modeling and assessing the processes and environmental effects of urban activities. In 2007, 
Table 1

Themes of this SV and the papers contained in each theme are listed in this table.

\begin{tabular}{|c|c|}
\hline & Authors \\
\hline \multicolumn{2}{|l|}{ Theme one: from civil infrastructure to ecological infrastructure: diagnoses and remedies of urban illnesses } \\
\hline $\begin{array}{l}\text { 1. A review of urban metabolism studies to identify key methodological choices for future harmonization and } \\
\text { implementation }\end{array}$ & Beloin-Saint-Pierre et al., 2017 \\
\hline 2. Comparing performance metrics for multi-resource systems: the case of urban metabolism & Ravalde and Keirstead, 2017 \\
\hline $\begin{array}{l}\text { 3. Urban metabolism profiles. An empirical analysis of the material flow characteristics of three metropolitan areas } \\
\text { in Sweden. }\end{array}$ & Rosado et al., 2016 \\
\hline $\begin{array}{l}\text { 4. Quantifying the emergy flow of an urban complex and the ecological services of a satellite town: a case study of } \\
\text { Zengcheng, China }\end{array}$ & Zhang et al., 2017 \\
\hline 5. Factor analysis of energy-related carbon emissions: a case study of Beijing & Fan and Lei, 2017 \\
\hline 6. The impact of urbanization on carbon emissions in developing countries: the U-Kaya method & Wu et al., 2016 \\
\hline 7. The effect of new-type urbanization on energy consumption in China: a spatial econometric analysis & Liu et al., 2017a \\
\hline 8. Assessing the energy-saving effect of urbanization in China based on STIRPAT model & Ji and Chen, 2017 \\
\hline 9. Communal carbon metabolism: methodology and case study & Lu et al., 2017 \\
\hline $\begin{array}{l}\text { 10. The driving force of water footprint under the rapid urbanization process: a structural decomposition analysis for } \\
\text { Zhangye city in China. }\end{array}$ & Feng et al., 2017 \\
\hline $\begin{array}{l}\text { 11. Comprehensive evaluation of different scale cities' sustainable development for economy, society, and ecological } \\
\text { infrastructure in China. }\end{array}$ & Sun et al., 2017a \\
\hline 12. Evaluating the trends of China's ecological civilization construction using a novel indicator system. & Zhang et al., 2016 \\
\hline 13. The spatial-temporal characteristics and health impacts of ambient fine particulate matter in China. & Song et al., 2016 \\
\hline 14. Identifying the main contributors of air pollution in Beijing & Li et al., 2017a \\
\hline \multicolumn{2}{|c|}{$\begin{array}{l}\text { Theme two: international experiences and lessons in urban "green-blue" ecological engineering to develop and enforce standards for restoration of natural and } \\
\text { social ecosystem services }\end{array}$} \\
\hline $\begin{array}{l}\text { 1. Stormwater wetlands for the enhancement of environmental ecosystem services: case studies for two retrofit } \\
\text { wetlands in Brisbane, Australia. }\end{array}$ & Greenway, 2017 \\
\hline $\begin{array}{l}\text { 2. Integrative assessment and management implications on ecosystem services loss of coastal wetlands due to } \\
\text { reclamation. }\end{array}$ & Sun et al., 2017b \\
\hline $\begin{array}{l}\text { 3. The role of monitoring sustainable drainage systems for promoting transition towards regenerative urban built } \\
\text { environments: a case study in the Valencian region, Spain. }\end{array}$ & Perales-Momparler et al., 2017 \\
\hline 4. The potential role of desalination in managing flood risks from dam overflows: the case of Sydney, Australia. & Turner et al., 2016 \\
\hline 5. Smart meter enabled informatics for economically efficient diversified water supply infrastructure planning. & Gurung et al., 2016 \\
\hline $\begin{array}{l}\text { 6. The impact of land-use change on water-related ecosystem services: a study of the Guishui River Basin, Beijing, } \\
\text { China. }\end{array}$ & Gao et al., 2017b \\
\hline 7. Urban agriculture in Mexico City; balancing between ecological, economic, social and symbolic value. & Dieleman, 2017 \\
\hline $\begin{array}{l}\text { 8. Metals in exposed-lawn soils from } 18 \text { urban parks and its human health implications in southern China's largest } \\
\text { city, Guangzhou. }\end{array}$ & Gu et al., 2016 \\
\hline $\begin{array}{l}\text { 9. Assessing the changes in the soil conservation ecosystem service and the causal factors in the Three Gorges } \\
\text { Reservoir area of China }\end{array}$ & Xiao et al., 2017 \\
\hline $\begin{array}{l}\text { 10. The impacts of socio-demographic, environmental, and individual factors on urban park visitation in Beijing, } \\
\text { China }\end{array}$ & Liu et al., 2017c \\
\hline \multicolumn{2}{|l|}{ Theme three: implementation of integrated urban waste management, recycling and treatment policies and facilities } \\
\hline 1. The door-to-door recycling scheme of household solid wastes in urban areas: a case study from Nagoya, Japan & Zheng et al., 2017 \\
\hline 2. Energy consumption and economic cost of typical wastewater treatment systems in Shenzhen, China. & Li et al., $2017 \mathrm{~b}$ \\
\hline $\begin{array}{l}\text { 3. Economic and Environmental Analysis of Five Chinese Rural Toilet Technologies Based on the Economic Input- } \\
\text { Output Life Cycle Assessment }\end{array}$ & Gao et al., 2017a \\
\hline \multicolumn{2}{|l|}{ Theme four: design and modify urban impervious surfaces through ecological engineering } \\
\hline $\begin{array}{l}\text { 1. A continuous dynamic feature of the distribution of soil temperature and horizontal heat flux next to external } \\
\text { walls in different orientations of construction sites in the autumn of Beijing, China }\end{array}$ & Zhou et al., 2017 \\
\hline $\begin{array}{l}\text { 2. Aggregate risk assessment of polycyclic aromatic hydrocarbons from dust in an urban human settlement } \\
\text { environment. }\end{array}$ & Xu et al., 2016 \\
\hline \multicolumn{2}{|l|}{ Theme five: urban aorta ecology, ecological mobility and livable corridors } \\
\hline $\begin{array}{l}\text { 1. The adoption of strategies for sustainable cities: a comparative study between Newcastle upon Tyne and } \\
\text { Florianópolis focused on urban mobility. }\end{array}$ & de Andrade Guerra et al., 2016 \\
\hline \multicolumn{2}{|l|}{ Theme six: integrative design criteria and cases of urban ecological infrastructure management } \\
\hline 1. Urban ecological infrastructure: An integrated network for ecosystem services and sustainable urban systems. & Li et al., 2017c \\
\hline 2. Infrastructure ecology: an evolving paradigm for sustainable urban development & Pandit et al., 2017 \\
\hline 3. Ecological inter-correlations in urban-rural development: an eco-city of China. & Wang et al., 2017 \\
\hline $\begin{array}{l}\text { 4. The optimization of urban ecological infrastructure network based on the changes of county landscape patterns: a } \\
\text { typical case study of ecological fragile zone located at Deng Kou (Inner Mongolia) }\end{array}$ & Yu et al., 2017 \\
\hline 5. Sustainable Buildings for Healthier Cities: Assessing the Co-benefits of Green Buildings in Japan & Balaban and Puppim de Oliveira, 2017 \\
\hline 6. To each their own? The greenhouse gas impacts of intra-household sharing in different urban zones. & Ala-Mantila et al., 2016 \\
\hline 7. Challenges of Developing Sustainable Neighborhoods in China & Shi et al., 2016 \\
\hline \multicolumn{2}{|l|}{ Theme seven: the roles of urban ecological infrastructure in industrial parks and industrial clusters } \\
\hline 1. Emergy evaluation for a low-carbon industrial park & Fang et al., 2017 \\
\hline 2. Quantifying direct and indirect carbon dioxide emissions of the Chinese tourism industry. & Meng et al., 2016 \\
\hline 3. Analysis of $\mathrm{CO} 2$ emissions embodied in China's bilateral trade: a non-competitive import Input-Output approach. & Liu et al., 2017c \\
\hline $\begin{array}{l}\text { 4. Uncertainty analysis for measuring greenhouse gas emissions in the building construction phase: a case study in } \\
\text { China. }\end{array}$ & Hong et al., 2016 \\
\hline
\end{tabular}

Kennedy et al. (2007) defined the UM concept as "the sum total of the technical and socioeconomic processes that occur in cities, resulting in growth, production of energy, and elimination of waste". Research on UM has become important in the past two decades. It has promoted the implementation of greenhouse gas accounting design and material flow accounting. 
In the paper, $\boldsymbol{A}$ review of urban metabolism studies to identify key methodological choices for future harmonization and implementation by Beloin-Saint-Pierre et al. (2017), a critical review of studies of urban metabolism was performed; consequently, new methodological choices are proposed for future research. The authors suggested that a network system modeling approach, a global life cycle perspective, and a multi-criterion assessment are strategic tools for improved environmental sustainability assessment. Principles such as benchmarking and uncertainty assessment were found to be essential performing consistent sustainability assessments.

In the paper, Comparing performance metrics for multiresource systems: the case of urban metabolism, Ravalde and Keirstead (2017) evaluated how urban metabolism studies could be used to support performance measures for urban resource consumption in view of the multi-resource trade-off (MRTP) in order to guide policy or investment decisions. The authors developed a novel framework which categorizes measures into two types: those that can be calculated from a system's aggregated inputs and outputs ('black-box' metrics, e.g., $C$ footprint) and those that require knowledge of resource conversion processes within the system ('gray-box' metrics). Based on the framework's application in fifteen cities around the world, the authors suggested improving urban metabolism accounting to assist gray-box metric calculations by providing greater detail about conversion processes and resource quality and by promoting these metrics among relevant decision-makers.

In the paper, Urban metabolism profiles. An empirical analysis of the material flow characteristics of three metropolitan areas in Sweden by Rosado et al. (2016), a framework for characterizing urban metabolism was provided using urban material flow accounting indicators as the basis. A material flow accounting study was conducted for three cities in Sweden (Stockholm, Gothenburg and Malmo) for the period 1996 to 2011. Based on the urban metabolism characteristics, three distinct profiles were documented: consumer-service, industrial, and transitioning. Policy implications and suggestions for future research were discussed.

Since the 1950s, metropolitan areas have dramatically expanded throughout the world; they typically consist of one or two core mega cities and a number of surrounding small and mediumsized cities (Gottmann, 1964). As connection nodes for central cities and peripheral areas, the small and medium-sized cities play an important role in realizing regional economic growth through participating in economic cycles and division (Fahmi et al., 2014). In China, many peri-urban counties or satellite towns with rich ecosystems were targeted as eco-conserving divisions that provide ecosystem services to a central city whose economic development is restricted. However, how this policy influences the sustainability of the satellite towns has seldom been studied, in-depth.

In the paper, Quantifying the emergy flow of an urban complex and the ecological services of a satellite town: a case study of Zengcheng, China by Zhang et al. (2017a), the sustainability and ecosystem services of Zengcheng, a satellite town of Guangzhou, were examined using a series of emergy indicators. The results showed that the sustainability of Zengcheng is lower than that of many developed cities and that its development is still reliant on resource consumption. However, Zengcheng possessed abundant ecosystem services that will or can increase the sustainability of the Guangzhou metropolitan area.

In the paper Factor analysis of energy-related carbon emissions: a case study of Beijing, Fan and Lei (2017) reviewed and compared the methods for factor analysis related to C-emissions, and the generalized Fisher index (GFI) decomposition method was used in a case study of Beijing. The results showed that the sustained growth of economic output in Beijing was the leading factor in C-emissions. Population size had a stimulatory effect on the growth of C-emissions during this period, whereas, energy intensity was the primary factor restraining C-emissions. Optimization of the energy structure had no obvious inhibitory effect on C-emissions. Adjusting the mode of economic development, controlling population size and improving energy efficiency were suggested for controlling C-emissions in Beijing.

In the paper, The Impact of Urbanization on Carbon Emissions in Developing Countries: The U-Kaya method by Wu et al. (2016) presented a modified Kaya Identity formula by including a direct urbanization factor to determine the relationship between energy consumption intensity, population growth, urbanization rates, urban and rural GDP per capita and the volume of $C$ emissions. The use of the method was demonstrated by forecasting China's likely C-emissions in 2020 under three different urbanization scenarios: the government-dominant mode, the market-dominant mode, and a hybrid government market-dominant mode. Policy implications of reducing C-emissions were identified.

In the paper, The effect of New-type Urbanization on Energy Consumption in China: A Spatial Econometric Analysis by Liu et al. (2017a) contributed to the literature by using an improved spatial econometric model (STIRPAT) to investigate the effects of urbanization on energy consumption in different regions of China. The impact of urbanization was disaggregated into direct and indirect impacts from the perspective of spatial econometrics. As the urbanization level increased by $1.0 \%$, energy consumption levels decrease by $0.089 \%$. It is essential to devote major efforts to energy conservation to achieve the new-types of more sustainable urbanization. In particular, disaggregating China's targets for controlling energy consumption into smaller targets for different regions can-contribute to controlling the growth of energy consumption.

In regard to the issue of urbanization, energy consumption and C-emissions, there are two streams of thought. One is that cities consume large amounts of energy and resources and produce various wastes and pollution and thus, are responsible for the emerging environmental crisis. (Zhang et al., 2014; UN-Habitat, 2016). In contrast, some scholars believe that leaders of cities can play key roles in combatting these problems, by implementing cleaner technologies and by improving energy efficiency (White, 1994; Wu and Wu, 2008; Romero-Lankao and Dodman, 2011).

In the paper, Assessing the energy-saving effect of urbanization in China based on STIRPAT model, Ji and Chen (2017) explored this divergence by using the Stochastic Impacts by Regression on Population, Affluence and Technology (STIRPAT) model to evaluate the energy-saving effect of China's urbanization based on provincial panel data. The results suggested that 1) urbanization induced energy consumption had a notable negative energy-saving effect; 2) the energy-saving effects of urbanization at different stages followed a U-shaped path; and 3) the energy-saving effects increased with income level. The outcomes may help us to better understand the causative relationships between energy consumption and urbanization. In addition, an in-depth causation analysis of the energy inefficiency of China's urbanization was performed and policy recommendations were developed for making improvements.

Urban communities are key elements in promoting low-carbon cities. The lens of C-metabolism in urban communities can help in exploring the characteristics of metabolic behavior and structure and the interactions among the urban environment, communities and households, thus unveiling the intrinsic drivers of C-emissions.

In the paper, Communal Carbon Metabolism: Methodology and Case Study by Lu et al. (2016) proposed a conceptual model of communal C-metabolism to trace the metabolic behaviors of urban communities and applied it to a typical community in Beijing. The results showed that the communal metabolic system was 
dominated mainly by the C-supply of household-induced energy from the urban environment. The energy and household sectors were the most active participants in the well-structured metabolic systems, and the low-carbon strategies should be implemented to mitigate local and regional emissions.

Ecological civilization (EC) construction has become one of the key strategies to address China's serious resource and environmental issues. However, how to define and how to assess EC are issues that urgently require further exploration.

In the paper, Evaluating the trends of China's ecological civilization construction using a novel indicator system Zhang et al (2016) constructed a people-oriented EC indicator system, composed of the flowing indicators: the Degree of Physiological Equilibrium (DPE), the Degree of Psychological Imbalance (DPI), the Degree of Imbalance between Humans and the Environment (DIHE), the Degree of Human Development (DHP), the Disharmony Degree of the Economy and the Environment (DDEE), and a composite index called the Ecological Civilization Index (ECI). This indicator system was used to investigate the trends in China's EC construction during the period from 1980 to 2010 based on statistical data. China's EC level declined during this study period. In this period, psychological problems and conflicts between humans and the environment were the key obstacles to China's EC progress.

In the paper, Comprehensive evaluation of different scale cities' sustainable development for economy, society, and ecological infrastructure in China by Sun et al. (2015a), a 22-indicator system was developed to comprehensively assess urban sustainability. This indicator system was applied to 277 Chinese cities, including megalopolises, large cities, and small or medium-sized cities, from 2000 to 2010 , based on statistical data. Sustainability was assessed using three different scales, and policy implications were discussed.

Water scarcity is a hindrance for the social and economic development of cities, especially in semi-arid areas (Cazcarro et al., 2013; White et al., 2015). Economic development and urbanization process generated huge impacts on water resource availability and quality. A comprehensive exploration of water consumption and its driving forces is therefore significant for understanding the water resource challenge faced by cities in semi-arid areas.

In the paper The driving force of water footprint under the rapid urbanization process: a structural decomposition analysis for Zhangye city in China, Feng et al. (2017) conducted an inputoutput analysis (IOA) and a structural decomposition analysis (SDA) to explore the water footprint (WF) of Zhangye city and its driving factors during the period 2001-2011. In particular, the urbanization level was incorporated into the SDA to depict the relationships between urbanization and WF. From the final demand perspective, structural effect was the principal driving factor that contributed to the growth of both urban and rural household WFs. From the sectoral categories scale perspective, the agriculture, forestry, animal husbandry, transportation communication and electronic equipment sectors were responsible for the variations in the total WF and household WF. Technological innovations and adjustments of the final demand structure were suggested as priorities in Zhangye to reduce the WF.

Air pollution is a major problem in many large cities worldwide. Human exposure to high levels of airborne particulate matter (PM) can reduce projected life expectancies by $1-5$ years (WHO, 2003; Chen et al., 2013). Airborne particulate matter presents a serious health threat to human beings all over the world, especially in China and India. Papers of previous research published in JCLP tentatively, assessed the human health impacts of air pollution in China (Chen et al., 2017), but more epidemiological studies are needed due to its complexity and significance.

In the paper, The spatial-temporal characteristics and health impacts of ambient fine particulate matter in China, Song et al.
(2016) explored the temporal and spatial characteristics of ambient airborne PM2.5 in China in 2013. Mortality, respiratory diseases, cardiovascular diseases, and chronic bronchitis were evaluated as four health endpoints attributable to PM2.5. The results showed that in terms of the health endpoints attributable to PM2.5, there were 763,595 deaths, 149,754 cases of cardiovascular diseases, 446,035 cases of respiratory disease, and 2,389,035 cases of chronic bronchitis due to the severe air pollution levels in China in 2013. This research was very important in clarifying some of the shortterm health impacts in China of high levels of PM2.5 pollution. Much more research is needed to investigate and to document the long-term impacts of human exposure to such high levels of air pollutants and on how to prevent or to minimize such pollutants at their sources.

In the paper, Identifying the main contributors of air pollution in Beijing, Li et al. (2015a) used an extended version of the IPAT model $(\mathrm{I}=$ impact, $\mathrm{P}=$ population, $\mathrm{A}=$ affluence, and $\mathrm{T}=$ technology) to identify the main contributors to air pollution in Beijing from 1989 to 2012. The results showed that the most influential factors affecting air pollution in Beijing were affluence and emission intensity. By analyzing the historical background, the authors concluded that the change in air pollution in Beijing was heavily policy driven. Measurements such as modifying the economic structure, changing to cleaner energy sources, limiting population growth (after 1995), and regulating the number and emissions of vehicles were proposed to help to reduce air pollution at the sources.

\subsection{Theme two: international experiences and lessons in urban "green-blue" ecological engineering to develop and enforce standards for restoration of natural and social ecosystem services}

Land-use changes are significant drivers of ecosystem service changes. In the paper, The impact of land-use change on waterrelated ecosystem services: a study of the Guishui River Basin, Beijing, China Gao et al. (2017b) explored how land-use changes affected water-related ecosystem services under rapid urbanization in Beijing from 1980 to 2011 using the InVest model. Four spatially explicit land-use scenarios, corresponding to water conservation, agricultural expansion, a combination scenario, and soil conservation, were developed, and their respective impacts upon ecosystem services were assessed. This research enriched our knowledge of the dynamics of ecosystem service with urbanization and landuse changes and was a good example of how ecosystem service research can help decision-makers to make better, land-use management decisions.

Coastal ecosystems provide homes for $50 \%$ of the world's population (Turner et al., 2000; MEA, 2005; Barbier et al., 2011). Unfortunately, during the past few decades, rapid urbanization, population growth and coastal reclamations have altered the physical and biochemical features of coastal ecosystems, which are jeopardizing the sustainable provision of ecosystem services (Dobson et al., 2006; Halpern et al., 2008). Conflicts between the development and conservation of ecosystem services have long been thorny problems for decision-makers (Carreño et al., 2012).

In the paper, Integrative assessment and management implications on ecosystem services loss of coastal wetlands due to reclamation, Sun et al. (2015b) modified a model for quantifying the ecosystem service values of different coastal system subtypes and used this model in a case study. Four major agriculture-related ecosystem services-food production, raw material supply, disturbance regulation, and water purification-were included in the model. The modified ecosystem service valuation models enabled the achievement of categorized management of coastal ecological infrastructures. Furthermore, this study documented how to 
integrate ecosystem service estimates into the assessment, management, planning, restoration, and compensation of coastal ecological infrastructures.

Sustainable drainage systems that mimic pre-development hydrology process are an alternative to conventional urban stormwater management and provide multiple benefits (Zedler and Kercher, 2005). However, transitions toward regenerative urban built environments that widely incorporate sustainable drainage systems are intrinsically innovative approaches, which encounter barriers such as limited evidence on the performance of these systems and poor involvement of different stakeholders.

To overcome such innovation-driven barriers, in the paper The role of monitoring sustainable drainage systems for promoting transition towards regenerative urban built environments: a case study in the Valencian region, Spain, Perales-Momparler et al. (2017) demonstrated the feasibility and suitability of six showcase projects for sustainable drainage systems. The acquired data, after being fully analyzed and presented to a group of key regional stakeholders, proved to be a valuable promoter of the desired transition, for example, financial support for implementation of sustainable drainage systems was included in the recent regional legislation. This research not only demonstrated the improved environmental performance of sustainable drainage systems but also provided an example of promoting the implementation of ecological infrastructure.

Assessing the changes in the soil conservation ecosystem service and the causal factors in the Three Gorges Reservoir area of China by Xiao et al. (2017) analyzed the spatial characteristics of soil conservation in China's Three Gorges Reservoir area based on the InVEST model and discussed the influencing factors. The soil conservation service of $83.4 \%$ of the total area increased. Slope and precipitation were the most important predictors of soil conservation ecosystem service.

In the paper, Stormwater wetlands for the enhancement of environmental ecosystem services: case studies for two retrofit wetlands in Brisbane, Australia, by Greenway (2017), the author examined and compared the environmental performance of two retrofitted wetlands with different designs based on reliable monitoring data and achieves gratifying results. Water quality indicators and macroinvertebrates were monitored from 2002 to 2004 . A clear improvement in water quality and biodiversity was observed. A favorable design to improve ecosystem services was suggested, and the possible deficiencies of the engineering were discussed. More importantly, the two wetlands are both 'retrofit' systems that were designed and constructed on existing brownfield sites. This research provided a good case for smart transitions from urban brownfield sites, with negative environmental impacts, to blue land, with multiple benefits.

In the paper Smart meter enabled informatics for economically efficient diversified water supply infrastructure planning, Gurung et al. (2016) used an innovative bottom-up approach to develop demand profiles based on smart meters, enabling comprehensive water end-use datasets (e.g., demand for shower water and tap water) to be obtained. Hydraulic model runs were conducted for various water savings scenarios across different planning horizons to determine the scheduling of augmentations in a water supply study area. Financial analysis was conducted to assess the economic performance of the scenarios.

The long-term effects of climate change are likely to result in a greater frequency of extreme droughts and floods in many regions (IPCC, 2012; IPCC, 2014). The shift in precipitation patterns increases the vulnerability of cities to various climate hazards, which calls for infrastructures with higher adaptation capacities, efficiencies and resiliencies.

To help achieve this goal, the paper The potential role of desalination in managing flood risks from dam overflows: the case of Sydney, Australia by Turner et al. (2016) explored the growing need to understand the relationship between drought, flooding and infrastructure optimization in the context of shifting precipitation patterns. A system dynamics model to support water resource management was suggested and demonstrated using available data from Sydney. The authors demonstrated the importance of optimizing existing and new water resources for multiple purposes and how system dynamics modeling can assist water service providers in these complex investigations.

It is estimated that 200 million urban residents produce food for the urban market, providing $15-20 \%$ of the world's food supply (Armar-Klemesu, 2000). Urban agriculture constitutes an important food and income source for citizens in developing countries, and it is also important in terms of food security and environmental effects in developed countries.

In the paper Urban agriculture in Mexico City; balancing ecological, economic, social and symbolic value, Dieleman (2017) reviewed the concept of and the policy framework for urban agriculture in cities worldwide. The author then discussed current practices in the peri-urban, suburban and interurban parts of Mexico City and analyzed them in terms of economic, ecological, social and symbolic dimensions. The author documented that Mexico City produced $20 \%$ of its own food but that the importance of this food production in economic terms was limited. The environmental implications of urban agriculture were limited but urban agriculture has potential if it is further promoted. However, its symbolic meaning was very important in Mexico City, as urban agriculture is now increasingly being viewed as a way to restore some of the pre-Hispanic practices of the Aztecs, particularly the Floating Gardens or Chinampas, that have largely been lost due to colonization.

Urban ecological infrastructure provides not only multiple natural ecosystem services but also important cultural ecosystem services. This is underscored in the paper, The impacts of sociodemographic, environmental, and individual factors on urban park visitation in Beijing, China by Liu et al. (2017b), in which the cultural ecosystem services of urban parks were evaluated by using a questionnaire in terms of park visitation. The relative contributions of the socio-demographic, environmental and individual factors in determining park use were identified and interventions and critical parameters to improve park usage were proposed.

Despite the multiple ecosystem services provided by urban parks, several researchers showed that park soil may be a sink for heavy metals. Metals in urban soils can be readily absorbed by humans through ingestion, inhalation, and dermal absorption, and they can pose threats to urban residents, especially to children and senior citizens, who are more susceptible to such threats and tend to use parks more often than other people (Miguel et al., 1997; Guney et al., 2010).

In the paper, Metals in exposed-lawn soils from 18 urban parks and its human health implications in southern China's largest city, Guangzhou by Gu et al. (2016) investigated the total concentrations and the fractionation of metals in surface-exposed lawn soils from eighteen urban parks in Guangzhou and assessed their impacts upon human health. The authors concluded that exposure to urban park soil does not pose a significant non-carcinogenic risk from the metals analyzed. The probabilities of $\mathrm{Cd}, \mathrm{Cr}$, and Ni posing carcinogenic risks to children and adults were negligible.

\subsection{Theme three: implementation of integrated urban waste management, recycling and treatment policies and facilities}

Wastewater treatment and reuse, a great potential alternative for relieving water shortage and an indispensable method of 
managing pollutants safely, has attracted considerable attention in China. The number of wastewater treatment plants in China has reached to 3272 in 2013, with a total handling capacity of 0.14 billion $\mathrm{t} /$ day. However, the wastewater treatment plants consume large amounts of energy. Thus, identifying the factors that influence energy consumption in wastewater treatment systems is important when seeking ways to save energy and to lower operational costs.

In the paper, Energy consumption and economic cost of typical wastewater treatment systems in Shenzhen, China Li et al. (2015a) investigated the energy efficiency and capacity of a wastewater treatment plants in Shenzhen. The biochemical treatment subprocess, the scale of the treatment plant and the technologies used were found to be the main contributors to energy consumption. Finally, upgrading treatment machine and equipment and improving the management level were found to be able to help to improve energy efficiency.

In the paper The door-to-door recycling scheme of household solid wastes in urban areas: a case study from Nagoya, Japan by Zheng et al. (2016), the authors established a better understanding of the 'door-to-door,' recycling scheme for household solid wastes (HSW) in Nagoya, Japan. Based on a SWOT analysis, the internal (strengths and weaknesses) and external (opportunities and threats) of the 'door-to-door,' recycling scheme for HSW were assessed. The study provided a good example of encouraging major stakeholders' involvement in HSW management. Four critical strategies (further developing residents' awareness of recycling, completing the insurance mechanism for the implementation of recycling systems, extending the responsibility of producers/industries, and conducting comprehensive research into waste management) were proposed for maintaining and developing the door-todoor recycling scheme for HSW.

Toilets are critical infrastructure for promoting public health. The current sanitation technology in developed countries is based on diluting human excreta with large volumes of centrally provided potable water, which requires great quantities of water and energy.

In the paper, Economic and environmental analysis of five Chinese rural toilet technologies based on the economic input and output life cycle assessment by Gao et al. (2017b), the authors designed comprehensive schemes for Chinese rural toilets, including standard flushing systems, rainwater harvesting flushing systems, and urine separation and composting systems, and five scenarios were developed. The economic net present value method and the economic input-output lifecycle assessment model were used to assess environmental impacts and cost-effectiveness. A mountainous village in the Mentougou District of Beijing was used as an example. The results showed that scenario five-urine diverting composting systems-outweighed the other four alternatives with respect to cost, even when applying different discount rates that range from $0 \%$ to $10 \%$. Scenario three-urine diversion and potable water flushing toilet-was a sub-optimal economic solution; the net present value was negative when the discount rate was over $8 \%$. The two technologies were proven to be viable options for standard flushing toilets. The impacts of the rising price of water on technology selection were analyzed. Finally, suggestions were given for the practical implementation of urine separation toilets and composting toilets. The economic benefits would be larger if the benefits of replacement of commercial nitrogen fertilizers were integrated into the assessments.

\subsection{Theme four: design and modify urban impervious surfaces through ecological engineering}

The increase in impervious surfaces is the one of the major contributors to environmental problems, along with urbanization. Impervious surfaces alter urban environments in many ways such as inhibiting water and gas exchange, altering hydrological cycling and surface heat flux, and changing the soil micro-organism community. However, empirical studies and comprehensive evaluation models of the compound ecological effects of impervious surfaces are still scarce.

Along that line, the paper A Continuous Dynamic Feature of the Distribution of Soil Temperature and Horizontal Heat Flux next to External Walls in Different Orientations of Construction Sites in the Autumn of Beijing, China by Zhou et al. (2017) explored the effects of urban construction and impervious surfaces on the soil heat environment and the underlying mechanisms by using an improved method named, Construction-Soil Micro Gradient Transect Observation. A quantitative model was generated and applied to estimate horizontal heat fluxes between a construction site and soil using a large amount of experimental data; this offers a useful tool to assess the effects of impervious surfaces on the soil heat environment. The results showed that construction sites were considered to be a heat source for soil and provide soil with thermal energy, leading to a higher soil temperature around construction sites in urban areas in the Autumn. This study focused on the horizontal heat impacts of urban construction on the soil of adjacent green spaces under different weather conditions in Autumn and helped us to understand the ecological relationships between urban heat islands and ecosystem processes.

In the paper Aggregate risk assessment of polycyclic aromatic hydrocarbons from dust in an urban human settlement environment by Xu et al. (2016), the authors developed an aggregate health risk assessment framework based on a multiple-pathways exposure model, dose-risk relationships and scenario analysis using dust as an environmental medium in the urban settlement context. A case study was conducted in Nangjing, and the results indicated that the non-carcinogenic risk and carcinogenic risk in Nanjing are currently acceptable but cannot be ignored in the long term. Future urban construction, especially residential construction, should be expanded to the south of the city rather than the west to minimize the human health risks, given the uneven spatial distribution of carcinogenic risks.

\subsection{Theme five: urban aorta ecology, ecological mobility and livable corridors}

One of the challenges posed by booming urban populations is the question of mobility. Urban transport has become an important element of sustainability strategies because of its roles in guiding urban development and material and energy flow and its contributions to various pollution-causing emissions.

In the paper, The adoption of strategies for sustainable cities: a comparative study between Newcastle upon Tyne and Florianópolis by de Andrade Guerra et al. (2016) the authors developed indicators to define models and best practices for sustainable public transportation through an extensive literature review. The transport infrastructure models in Newcastle and Florianópolis were compared. The authors recommended the establishment and usage of coherent land use and transit plans, a regional metro system, bike path expansion and the adjustment of new apartment and commercial complexes to increase the sustainability of the transport system in Florianópolis.

\subsection{Theme six: integrative design criteria and cases of urban ecological infrastructure management}

The dramatic increases in the urban population worldwide and the rapid expansion of impervious urban surfaces are increasing concerns about more than just the quality of human life. Researchers are concerned about the losses of ecosystem services 
and the stability and security of urban ecosystems and infrastructures.

In the review paper, Urban ecological infrastructure: An integrated network for ecosystem services and sustainable urban systems by Li et al. (2015b), that authors defined "urban ecological infrastructure" and proposed an integrated framework in which the infrastructure network provided ecosystem services and sustainable urban systems in changing landscapes and climates. The authors defined the UEI as an organic integration of blue (waterbased), green (vegetated), and gray (non-living) landscapes, combined with exits (outflows, treatment, or recycling) and arteries (corridors) at an ecosystem scale. Case studies were presented to document the integrative design of UEI and its system performance. This comprehensive conceptual framework can help city planners to facilitate rational urban development and can help to improve urban ecosystem services and regional sustainability. Institutional and political barriers to and enablers of such networks were also discussed.

In another review paper, Infrastructure ecology: an evolving paradigm for sustainable urban Development by Pandit et al, (2017), the authors highlighted that sustainable cities rely on more productive, efficient and resilient infrastructure. Unfortunately, the current paradigm of urban infrastructure development is fragmented in its approach and lacks a systematic perspective. The authors emphasized that urban infrastructure systems are analogous to ecological systems because they are interconnected, complex and adaptive components that exchange materials, information and energy among themselves and to and from the environment and because they exhibit characteristic scaling properties that can be expressed by Zipf's Law. Analyzing them together as a whole, provides a better understanding of their dynamics and interactions and enables system-level optimization. This "infrastructure ecology" approach can help in urban (re) development that requires lower investments of financial and natural resources in a more sustainable way (e.g., uses less materials and energy and generates less waste) and in a more resilient approach, which can enable implementation of a greater number of more equitable opportunities for the creation of wealth and comfort. Twelve guiding principles for infrastructure ecology were proposed, which provide valuable guidance for urban planners, engineers and other decision-makers.

The ecological infrastructure network at the county scale is the foundation of urban sustainable development and is of key significance for ensuring the stable development of cities in arid areas.

In the paper The optimization of urban ecological infrastructure network based on the changes of county landscape patterns: a typical case study of ecological fragile zone located at Deng Kou by Yu et al. (2016), the authors investigated a series of landscape indicators and developed an improved minimum cumulative resistance (MCR) model to assess the ecological infrastructure network based on Thematic Mapper (TM) images from 2000 to 2007 and Operational Land Imager (OLI) images from 2014. The authors concluded that the urban area of Deng Kou expanded each year through an obvious urbanization process. The researchers documented that the county landscapes were immensely damaged in 2014. The authors developed an optimized network of urban ecological infrastructure at the county scale.

Ecological inter-correlations in urban-rural areas have key roles in changes to the unobserved environmental effects of urban pollution, energy use inefficiency, and cultivated land losses. In the paper Ecological inter-correlation in urban-rural development: an ecocity of China by Wang et al., 2017, the authors underscored that unequal economic growth in an urban-rural area resulted in variable eco-efficiency in industrial production in the urban areas, which increased the risks of environmental effects in the adjacent suburban and rural areas and directly had unobserved, spatiotemporally environmental effects. A case study in Gaoyou, China, was conducted, which documented that the ecological intercorrelations, to some extent, sustained the unobserved environmental effects, thereby, affecting regional environmental degradation.

Sustainable neighborhoods have been attracting an increasing level of attention from both industry and government. Several factors may impede the development of sustainable neighborhoods.

In the paper, Challenges of developing sustainable neighborhoods in China by Shi et al. (2016), the authors explored the relationships among barriers to sustainable neighborhood development. A hierarchical structural model was developed via interpretative structural modeling, and was then followed by a classification using Matrice d'Impacts Croisés Multiplication Appliquée á un Classeement (MICMAC) analysis. Lack of supporting policy, national standards, assessment tools and unsustainable planning were identified as the main barriers. Top priority should be assigned to address these issues appropriately to facilitate the development of more livable and sustainable neighborhoods.

The concept of sustainable (or green) building is a recent response to addressing environmental and health problems that stem from buildings and to reducing the impacts of the building sector on the natural environment. In recent decades, increased attention has been given to constructing green buildings and to renovating existing buildings using green technologies. Despite progress in the development of the sustainable building concepts and approaches, the 'greening' of buildings has not taken place on a wider scale in either developed or developing countries.

In the paper, Sustainable Buildings for Healthier Cities: Assessing the Co-benefits of Green Buildings in Japan by Balaban and Puppim de Oliveira (2017), the authors noted that widespread implementation of the concept has been hindered by economic and policy-relevant challenges and that demonstrating the multiple benefits that sustainable buildings deliver could help overcome these challenges. The authors documented the extent to which green buildings can generate co-benefits, and underlined the opportunities and barriers to pushing the green building agenda forward. The authors confirmed that green and sustainably renovated buildings can provide significant benefits in terms of reducing energy consumption and $\mathrm{CO}_{2}$ emissions, in reducing costs, and in improving the health status of building users. The projected reductions in energy consumption corresponds to energy cost savings of US\$ 1-1.5 million per year per building. It was recommended that the public sector should take actions to accelerate the number of green buildings that are built by providing fiscal support, technical assistance and policy reforms.

In the article, To each their own? The greenhouse gas impacts of intra-household sharing in different urban zones by Ala-Mantila et al. (2016), the authors explored the relationships among household sizes, urban structures, and greenhouse gas impacts on lifestyles. The authors argued that decreases in household size and increases in the demand for housing across the globe, which are driven by urbanization and multiple socio-economic trends, pose huge environmental challenges. The authors documented that there are connections between intra-household sharing and urban zones: households in peri-urban settings benefited the most from an additional household member. However, the effects were not uniform, and the economies of scale for household size have a bigger greenhouse gas (GHG) mitigating effect in less dense spatial locations. In inner-urban areas, increasing sharing has the potential to achieve the promise of inner-city living being the most GHGefficient way of living. The authors suggested that behavioral changes must occur both within and outside the households to promote intra-household sharing. 
3.7. Theme seven: the roles of urban ecological infrastructure in industrial parks and industrial clusters

Low-carbon industrial parks are the basic units of eco-city development, contributing significantly to environmental protection and C-emissions reduction. In the article, Emergy evaluation for a low-carbon industrial park by Fang et al. (2017), the authors used an embodied carbon accounting framework and a carbon indicator system based on emergy analysis that was used to identify the input-output structure and C-emission flows of an industrial park. Using a case study of a typical industrial park in Beijing, the authors documented that the park can sustain a balance between the embodied C-emission levels and their environmental supporting ability such that the environmental remediation cost of total production is relatively small. This framework will help planners in the design of industrial parks, to improve resource use efficiency and to reduce the environmental impacts of proper waste management.

The assessment of C-emissions in various industrial sectors is a very popular area in industrial ecology. The Intergovernmental Panel on Climate Change asserted that the building sector represented $40 \%$ of total energy consumption and $25 \%$ of global total $\mathrm{CO}_{2}$ emissions (IEA, 2007; Metz et al., 2007). In China, the large scale of construction, along with urbanization, make this challenge even greater. Life cycle assessment (LCA) is a widely used and effective tool for improving environmental management. However, any uncertainty in the producing stages affects the accuracy of LCA results.

Thus, in the article, Uncertainty Analysis for Measuring Greenhouse Gas Emissions in the Building Construction Phase: A Case Study in China by Hong et al. (2016), the authors developed a multi-method-based analytical framework, which can systematically identify the uncertainty sources and quantify the uncertainties bundled in construction activities. This framework avoids the misinterpretation of final results during the decision-making processes. Critical parameters that influence C-emissions during building construction were identified. Major uncertainty sources during building construction and strategies to mitigate uncertainties from different sources were addressed by the authors.

In the paper, Quantifying direct and indirect carbon dioxide emissions of the Chinese tourism industry by Meng et al. (2016), the authors employed improved methods to assess the C- emissions of the Chinese tourism industry. Their work is important because tourism is not a traditional sector in the System of National Accounts; consequently, C-emissions data for the tourism industry are not available on a national scale. A top-down approach was used to measure national C-emissions from tourism by combining the Tourism Satellite Account and the Input-Output model for productive industry. The results showed that the C-emissions of the Chinese tourism industry accounted for $2.489 \%, 2.425 \%, 2.439 \%$ and $2.447 \%$ of the total $\mathrm{C}$ emission of all industries in China in 2002, 2005, 2007 and 2010, respectively. Compared with the manufacturing industry, the tourism industry emitted less pollution and consumed less energy. The advantages and shortcomings of the top-down and bottom-up approaches and suggestions for making improvements were discussed by the authors in order to improve future research on C-emissions from tourism.

China has become the world's largest importer and exporter with a $47 \%$ dependence on foreign trade. Assessment of the $\mathrm{CO}_{2}$ emissions from international trade is important in allocating the responsibility for reducing C-emissions internationally; thus, a national C-reduction policy has drawn increasing attention. The embodied $\mathrm{CO}_{2}$ emissions in China's trade have been assessed by many researchers with very different results, owing to the use of varying methods and data (Su and Ang, 2013; Jiang et al., 2015).
In that context, in the paper, Analysis of $\mathbf{C O}_{2}$ Emissions Embodied in China's Bilateral Trade: A Non-Competitive Import Input-Output Approach, by Liu et al. (2016), the authors developed a modified, non-competitive import input-output method to remeasure embodied $\mathrm{CO}_{2}$ in bilateral trade between China and its major trading partners and case study was conducted based on input-output table data from 2007. The $\mathrm{CO}_{2}$ emissions embodied in China's exports in 2007 were 878 million tons less than previous estimates. The C-emissions embodied in China's imports were 478 million tons, and the major contributors were countries other than the three major economies (the USA, the EU, and Japan). Because the $\mathrm{CO}_{2}$ emissions embodied in China's trade were not as high as previously predicted, China should place more emphasis on its own energy saving and emissions reduction strategies to mitigate $\mathrm{CO}_{2}$ emission, such as improving efficiency in energy consumption and in using more clean and renewable energies to reduce the proportion of coal in the national energy consumption structure.

\section{Conclusions}

This SV included high-quality papers on theories and practices in UEI and urban sustainability. The authors comprehensively addressed a wide range of issues such as UEI and urban environmental problems, urban metabolism, ecosystem services, energy consumption, climate changes, and water resource conservation from diverse perspectives. In particular, the authors of the papers in this SV promoted the holistic view and co-benefits of UEI management, which differed from traditional perspectives. The concepts, principles, theories, innovative assessment models, successful experiences, barriers to and enablers of UEI implementation were investigated and helpful recommendations for ways to make improvements were mad, which provide a solid foundation and can provide inspiration to catalyze sustainable urbanization. The editorial team of this SV solicits readers' feedback and recommendations for the next thousand steps!

\section{Acknowledgments}

This research was funded by the National Natural Science Foundation of China (71273254, 71533004, 71403145, 71561137002). We especially thank Professor Rusong Wang for his great contribution and help on the initiation and design of this special volume (SV). Unfortunately, Professor Rusong Wang passed away on November 28, 2014. The publication of this SV is also in memory of him. We will remember him forever.

\section{References}

Ala-Mantila, S., Ottelin, J., Heinonen, J., Junnila, S., 2016. To each their own? The greenhouse gas impacts of intra-household sharing in different urban zones. J. Clean. Prod. 135, 356-367.

Armar-Klemesu, M., 2000. Urban agriculture and food security, nutrition and health. In: Bakker, N., Dubbeling, M., Gundel, S., Sabel-Koschella, U., de Zeeuw, H. (Eds.), Growing Cities, Growing Food: Urban Agriculture on the Policy Agenda. A Reader on Urban Agriculture. GTZ/DSE, Germany.

Bai, X. 2007. Industrial ecology and the global impacts of cities. J. Ind. Ecol. 11, 1-6.

Balaban, O., Puppim de Oliveira, J.A., 2017. Sustainable buildings for healthier cities: assessing the co-benefits of green buildings in Japan. J. Clean. Prod. 163, S68-S78. http://dx.doi.org/10.1016/j.jclepro.2016.01.086.

Barbier, E.B., Hacker, S.D., Kennedy, C., Koch, E.W., Stier, A.C., Silliman, B.R., 2011. The value of estuarine and coastal ecosystem services. Ecol. Monogr. 81 (2), 169-193.

Beloin-Saint-Pierre, D., Rugani, B., Lasvaux, S., Mailhac, A., Popovici, E., Sibiude, G. Benetto, E., Schiopu, N., 2017. A review of urban metabolism studies to identify key methodological choices for future harmonization and implementation. J. Clean. Prod. 163, S223-S240. http://dx.doi.org/10.1016/j.jclepro.2016.09.014.

Carreño, L., Frank, F.C., Viglizzo, E.F., 2012. Tradeoffs between economic and ecosystem services in Argentina during 50 years of land-use change. Agric. Ecosyst. Environ. 154, 68-77. 
Cazcarro, R., Duarte, J., Sánchez-Chóliz, 2013. Economic growth and the evolution of water consumption in Spain: a structural decomposition analysis. Ecol. Econ. 96, 51-61.

Chen, Y., Ebenstein, A., Greenstone, M., Li, H., 2013. Evidence on the impact of sustained exposure to air pollution on life expectancy from China's Huai River policy. P. Natl. Acad. Sci. 110, 12936-12941.

Chen, X.Y., Shao, S., Tian, Z.H., Xie, Z., Yin, P., 2017. Impacts of air pollution and its spatial spillover effect on public health based on China's big data sample. J. Clean. Prod. 142 (part 2), 915-925. http://dx.doi.org/10.1016/j.jclepro.2016.02.119.

de Andrade Guerra, J.B.S.O., Pereira Ribeiro, J.M., Fernandez, F., Bailey, C., Barbosa, S.B., da Silva Neiva, S., 2016. The adoption of strategies for sustainable cities: a comparative study between Newcastle and Florianópolis focused on urban mobility. J. Clean. Prod. 113, 681-694.

Dieleman, H., 2017. Urban agriculture in Mexico City; balancing between ecological, economic, social and symbolic value. J. Clean. Prod. 163, S156-S163. http:// dx.doi.org/10.1016/j.jclepro.2016.01.082.

Dobson, A., Lodge, D., Alder, J., Cumming, G., Keymer, J., McGlade, J., Mooney, H., Rusak, J.A., Sala, O., Wolters, V., Wall, D., Winfree, R., Xenopoulos, M., 2006. Habitat loss, trophic collapse, and the decline of ecosystem services. Ecology 87, 1915-1924.

Fahmi, F.Z., Hudalah, D., Rahayu, P., Woltjer, J., 2014. Extended urbanization in small and medium-sized cities: the case of Cirebon, Indonesia. Habitat. Int. 42, 1-10.

Fan, F., Lei, Y., 2017. Factor analysis of energy-related carbon emissions: a case study of Beijing. J. Clean. Prod. 163, S277-S283. http://dx.doi.org/10.1016/j.jclepro.2015.07.094.

Fang, D., Chen, B., Hayat, T., Alsaedi, A., 2017. Emergy evaluation for a low-carbon industrial park. J. Clean. Prod. 163, S392-S400. http://dx.doi.org/10.1016/ j.jclepro.2015.10.122.

Feng, L., Chen, B., Hayat, T., Alsaedi, A., Ahmad, B., 2017. The driving force of water footprint under the rapid urbanization process: a structural decomposition analysis for Zhangye city in China. J. Clean. Prod. 163, S322-S328. http:// dx.doi.org/10.1016/j.jclepro.2015.09.047.

Gao, H., Zhou, C., Li, F., Han, B., Li, X., 2017a. Economic and environmental analysis of five Chinese rural toilet technologies based on the economic input-output life cycle assessment. J. Clean. Prod. 163, S379-S391. http://dx.doi.org/10.1016/ j.jclepro.2015.12.089.

Gao, J., Li, F., Gao, H., Zhou, C., Zhang, X., 2017b. The impact of land-use change on waterrelated ecosystem services: a study of the Guishui River Basin, Beijing, China. J. Clean. Prod. 163, S148-S155. http://dx.doi.org/10.1016/j.jclepro.2016.01.049.

Gates, J.E., Giffen, N.R., 1991. Neotropical migrant birds and edge effects at a foreststream ecotone. Wilson Bull. 103, 204-217.

Gottmann, 1964. Megalopolis: the Urbanized Northeastern Seaboard of the United States. MIT Press, Cambridge, MA, USA.

Greenway, M., 2017. Stormwater wetlands for the enhancement of environmental ecosystem services: case studies for two retrofit wetlands in Brisbane, Australia. J. Clean. Prod. 163, S91-S100. http://dx.doi.org/10.1016/j.jclepro.2015.12.081.

Gu, Y.-G., Lin, Q., Gao, Y.P., 2016. Metals in exposed-lawn soils from 18 urban parks and its human health implications in southern China's largest city, Guangzhou. J. Clean. Prod. 115, 122-129.

Guney, M., Zagury, G.J., Dogan, N., Onay, T.T., 2010. Exposure assessment and risk characterization from trace elements following soil ingestion by children exposed to playgrounds, parks and picnic areas. J. Hazard. Mater. 182, 656-664.

Gurung, T.R., Stewart, R.A., Beal, C.D., Sharma, A.K., 2016. Smart meter enabled informatics for economically efficient diversified water supply infrastructure planning. J. Clean. Prod. 135, 1023-1033.

Halpern, S., Walbridge, K.A., Selkoe, C.V., Kappel, F., Micheli, C.D., Agrosa, J.F., Bruno, K.S. Casey, C., Ebert, H.E., Fox, R., Fujita, D., Heinemann, H.S., Lenihan, E.M.P., Madin, M.T., Perry, E.R., Selig, M., Spalding, R., Steneck, R., Watson, 2008. A global map of human impact on marine ecosystems. Science 319, 948-952.

Hanski, I., 1997. In: Tilman, D., Kareiva, P. (Eds.), Predictive and Practical Metapopulation Models: the Incidence Function Approach, pp. 21-45.

Hartig, T., Kahn, P.H., 2016. Living in cities, naturally. Science 352, 938-940.

Hong, J., Shen, G.Q., Peng, Y., Feng, Y., Mao, C., 2016. Uncertainty analysis for measuring greenhouse gas emissions in the building construction phase: a case study in China. J. Clean. Prod. 129, 183-195.

IEA, 2007. World Energy Outlook 2007: China and India Insights. Organisation for Economic Co-operation and Development.

IPCC, 2012. Managing the Risks of Extreme Events and Disasters to Advance Climate Change Adaptation (Special Report of the Intergovernmental Panel on Climate Change). Cambridge University Press, Cambridge, UK and New York, NY.

IPCC, 2014. Freshwater Resources. Climate Change 2014: Impacts, Adaptation, and Vulnerability. Part a: Global and Sectoral Aspects, Working Group II Contribution to the Fifth Assessment Report of the Intergovernmental Panel on Climate Change. Cambridge University Press, Cambridge, UK, pp. 229-270.

Ji, X., Chen, B., 2017. Assessing the energy-saving effect of urbanization in China based on stochastic impacts by regression on population, affluence and technology (STIRPAT) model. J. Clean. Prod. 163, S306-S314. http://dx.doi.org/10.1016/ j.jclepro.2015.12.002.

Jiang, X., Liu, Y., Zhang, J., Zu, L., Wang, S., Green, C., 2015. Evaluating the role of international trade in the growth of China's $\mathrm{CO}_{2}$ emission. J. Syst. Sci. Complex. 28 (4), 907-924.

Kennedy, C., Cuddihy, J., Engel-Yan, J., 2007. The changing metabolism of cities. J. Ind. Ecol. 11, 43-59.

Li, S., Feng, K., Li, M., 2017a. Identifying the main contributors of air pollution in Beijing. J. Clean. Prod. 163, S359-S365. http://dx.doi.org/10.1016/j.jclepro.2015.10.127.

Li, W., Li, L., Qiu, G., 2015b. Energy consumption and economic cost of typical wastewater treatment systems in Shenzhen, China. J. Clean. Prod. 163, S374-S378. http://dx.doi.org/10.1016/j.jclepro.2015.12.109.

Li, F., Liu, X.S., Zhang, X.L., Zhao, D., Liu, H.X., Zhou, C.B., Wang, R.S., 2017c. Urban ecological infrastructure: an integrated network for ecosystem services and sustainable urban systems. J. Clean. Prod. 163, S12-S18. http://dx.doi.org/10.1016/ j.jclepro.2016.02.079.

Liu, H., Li, F., Xu, L., Han, B., 2017a. The impact of socio-demographic, environmental, and individual factors on urban park visitation in Beijing, China. J. Clean. Prod. 163, S181-S188. http://dx.doi.org/10.1016/j.jclepro.2015.09.012.

Liu, Y., Xiao, H., Lv, Y., Zhang, N., 2017b. The effect of new-type urbanization on energy consumption in China: a spatial econometric analysis. J. Clean. Prod. 163, S299-S305. http://dx.doi.org/10.1016/j.jclepro.2015.10.044.

Liu, Y., Chen, S., Chen, B., Yang, W., 2017c. Analysis of $\mathrm{CO}_{2}$ emissions embodied in China's bilateral trade: a non-competitive import input-output approach. J Clean. Prod. 163, S410-S419. http://dx.doi.org/10.1016/j.jclepro.2016.02.085.

Lu, Y., Chen, B., Hayat, T., Alsaedi, A., 2017. Communal carbon metabolism: methodology and case study. J. Clean. Prod. 163, S315-S321. http://dx.doi.org/10.1016 j.jclepro.2015.10.137.

McDonnell, M.J., MacGregor-Fors, I., 2016. The ecological future of cities. Science 352, 936-938.

Meng, W., Xu, L., Hu, B., Zhou, J., Wang, Z., 2016. Quantifying direct and indirect carbon dioxide emissions of the Chinese tourism industry. J. Clean. Prod. 126 586-594.

Metz, B., Davidson, O.R., Bosch, P.R., Dave, R., Meyer, L.A., 2007. Contribution of Working Group III to the Fourth Assessment Report of the Intergovernmental Panel on Climate Change.

Miguel, E.d., Llamas, J.F., Chacón, E., Berg, T., Larssen, S., Røyset, O., Vadset, M., 1997. Origin and patterns of distribution of trace elements in street dust: unleaded petrol and urban lead. Atmos. Environ. 31, 2733-2740.

Millennium Ecosystem Assessment (MEA), 2005. Ecosystems and Human Well-being. Synthesis Island Press, Washington, D. C.

Nicholas, S.W., Julia, F.-U., Brad, W., David, M., 2016. Cities are the future. Science 352, 904-905.

Pandit, A., Minné, E.A., Li, F., Brown, H., Jeong, H., James, J.-A.C., Newell, J.P., Weissburg, M., Chang, M.E., Xu, M., Yang, P., Wang, R., Thomas, V.M., Yu, X., Lu, Z., Crittenden, J.C., 2017. Infrastructure ecology: an evolving paradigm for sustainable urban development. J. Clean. Prod. 163, S19-S27. http:// dx.doi.org/10.1016/j.jclepro.2015.09.010.

Perales-Momparler, S., Andrés-Doménech, I., Hernández-Crespo, C., VallésMorán, F., Martín, M., Escuder-Bueno, I., Andreu, J., 2017. The role of monitoring sustainable drainage systems for promoting transition towards regenerative urban built environments: a case study in the Valencian region, Spain. J. Clean. Prod. 163, S113-S124. http://dx.doi.org/10.1016/j.jclepro.2016.05.153.

Ravalde, T., Keirstead, J., 2017. Comparing performance metrics for multi-resource systems: the case of urban metabolism. J. Clean. Prod. 163, S241-S253. http:// dx.doi.org/10.1016/j.jclepro.2015.10.118.

Romero-Lankao, P., Dodman, D., 2011. Cities in transition: transforming urban centers from hotbeds of GHG emissions and vulnerability to seedbeds of sustainability and resilience: introduction and editorial overview. Curr. Opin. Environ. Sustain 3, 113-120.

Rosado, L., Kalmykova, Y., Patrício, J., 2016. Urban metabolism profiles. An empirica analysis of the material flow characteristics of three metropolitan areas in Sweden. J. Clean. Prod. 126, 206-217.

Shi, Q., Yu, T., Zuo, J., Lai, X., 2016. Challenges of developing sustainable neighborhoods in China. J. Clean. Prod. 135, 972-983.

Song, Y., Wang, X., Maher, B.A., Li, F., Xu, C., Liu, X., Sun, X., Zhang, Z., 2016. The spatial-temporal characteristics and health impacts of ambient fine particulate matter in China. J. Clean. Prod. 112, 1312-1318.

Su, B., Ang, B.W., 2013. Input-output analysis of $\mathrm{CO}_{2}$ emissions embodied in trade: competitive versus non-competitive imports. Energy Policy 56 (5), 83-87.

Sun, X., Liu, X., Li, F., Tao, Y., Song, Y., 2017a. Comprehensive evaluation of different scale cities' sustainable development for economy, society, and ecological infrastructure in China. J. Clean. Prod. 163, S329-S337. http://dx.doi.org/10.1016/ j.jclepro.2015.09.002.

Sun, X., Li, Y., Zhu, X., Cao, K., Feng, L., 2017b. Integrative assessment and management implications on ecosystem services loss of coastal wetlands due to reclamation. J. Clean. Prod. 163, S101-S112. http://dx.doi.org/10.1016/ j.jclepro.2015.10.048.

Turner, C.K., van den Bergh, J.C.J.C.M., Söderqvist, T., Barendregt, A., van der Straaten, J., Maltby, E., van Ierland, E., 2000. Ecological-economic analysis of wetlands: scientific integration for management and policy. Ecol. Econ. 35, 7-23.

Turner, A., Sahin, O., Giurco, D., Stewart, R., Porter, M., 2016. The potential role of desalination in managing flood risks from dam overflows: the case of Sydney, Australia. J. Clean. Prod. 135, 342-355.

UN-Habitat, 2016. Urbanization and Development: Emerging Futures. World Cities Report 2016. United Nations Human Settlements Programme. http://www. unhabitat.org.

United Nations, 2012. Department of Economic and Social Affairs. Population Division, New York.

Wang, Z., Deng, X., Wang, P., Chen, J., 2017. Ecological intercorrelation in urban-rural development: an eco-city of China. J. Clean. Prod. 163, S28-S41. http:// dx.doi.org/10.1016/j.jclepro.2016.02.120.

White, R., 1994. Strategic decisions for sustainable urban development in the third world. Third World Plan. Rev. 16, 103-116.

White, D.J., Feng, K.S., Sun, L.X., Hubacek, K., 2015. A hydro-economic MRIO anlysis 
of the Haihe River Basin's water footprint and water stress. Ecol. Model. http:// dx.doi.org/10.1016/j.ecomodel.2015.01.017.

WHO, 2003. Health Aspects of Air Pollution with Particulate Matter, Ozone and Nitrogen Dioxide. Report 2003 on a WHO Working Group (Bonn).

Wolman, A., 1965. The urban metabolism of cities. Sci. Am. 156-174.

Wu, L.Y., Wu, W.J., 2008. Discussion and Advice on Urbanization Path with Chinese Characteristic. The Commercial Press, Beijing (In Chinese).

Wu, Y., Shen, J., Zhang, X., Skitmore, M., Lu, W., 2016. The impact of urbanization on carbon emissions in developing countries: a Chinese study based on the U-Kaya method. J. Clean. Prod. 135, 589-603.

Xiao, Q., Hu, D., Xiao, Y., 2017. Assessing changes in soil conservation ecosystem services and causal factors in the Three Gorges Reservoir region of China. J. Clean. Prod. 163, S172-S180. http://dx.doi.org/10.1016/j.jclepro.2016.09.012.

Xu, L., Shu, X., Hollert, H., 2016. Aggregate risk assessment of polycyclic aromatic hydrocarbons from dust in an urban human settlement environment. J. Clean. Prod. 133, 378-388.

Yu, K.J., Han, X.L., Zhu, Q., 2007. Ecological infrastructure as a Synthetic Solution to urban environmental Problems. J. Nat. Resour. 22, 808-816.

Yu, Q., Yue, D., Wang, J., Zhang, Q., Li, Y., Yu, Y., Chen, J., Li, N., 2017. The optimization of urban ecological infrastructure network based on the changes of county landscape patterns: a typical case study of ecological fragile zone located at Deng Kou (Inner Mongolia). J. Clean. Prod. 163, S54-S67. http://dx.doi.org/ 10.1016/j.jclepro.2016.05.014.

Zedler, J.B., Kercher, S., 2005. Wetland resources: status, trends, ecosystem services, and restorability. Annu. Rev. Environ. Resour. 30, 39-74.

Zhang, B., Qiao, H., Chen, B., 2014. Embodied energy uses by China's four municipalities: a study based on multi-regional input-output model. Ecol. Model. http:/ dx.doi.org/10.1016/j.ecolmodel.2014.10.007.

Zhang, X., Wang, Y., Qi, Y., Wu, J., Liao, W., Shui, W., Zhang, Y., Deng, S., Peng, H., Yu, X., Qi, H., 2016. Evaluating the trends of China's ecological civilization construction using a novel indicator system. J. Clean. Prod. 133, 910-923.

Zhang, J., Wang, Y., Wang, C., Wang, R., Li, F., 2017. Quantifying the emergy flow of an urban complex and the ecological services of a satellite town: a case study of Zengcheng, China. J. Clean. Prod. 163, S267-S276. http://dx.doi.org/10.1016/ j.jclepro.2016.02.059.

Zheng, P., Zhang, K., Zhang, S., Wang, R., Wang, H., 2017. The door-to-door recycling scheme of household solid wastes in urban areas: a case study from Nagoya, Japan. J. Clean. Prod. 163, S366-S373. http://dx.doi.org/10.1016/ j.jclepro.2016.03.106.
Zhou, H., Li, Y., Xu, K., Zhang, H., Hu, D., Wang, X., Han, F., Wang, X., 2017. A continuous dynamic feature of the distribution of soil temperature and horizontal heat flux next to external walls in different orientations of construction sites in the autumn of Beijing, China. J. Clean. Prod. 163, S189-S198. http:// dx.doi.org/10.1016/j.jclepro.2015.10.120.

Feng Li*, Hongxiao Liu State Key Laboratory of Urban and Regional Ecology, Research Center for Eco-Environmental Sciences, Chinese Academy of Sciences, Beijing 100085, China

University of Chinese Academy of Sciences, Beijing 100049, China

Donald Huisingh Institute for a Secure and Sustainable Environment, University of Tennessee, Knoxville, TN, USA

Yutao Wang

Institute of Ecology and Biodiversity, Shandong University, Jinan 250100, China

Rusong Wang

State Key Laboratory of Urban and Regional Ecology, Research Center for Eco-Environmental Sciences, Chinese Academy of Sciences, Beijing 100085, China

* Corresponding author. State Key Laboratory of Urban and Regional Ecology, Research Center for Eco-Environmental Sciences, Chinese Academy of Sciences, Beijing 100085, China. E-mail address: lifeng@rcees.ac.cn (F. Li).

Available online 25 November 2016 